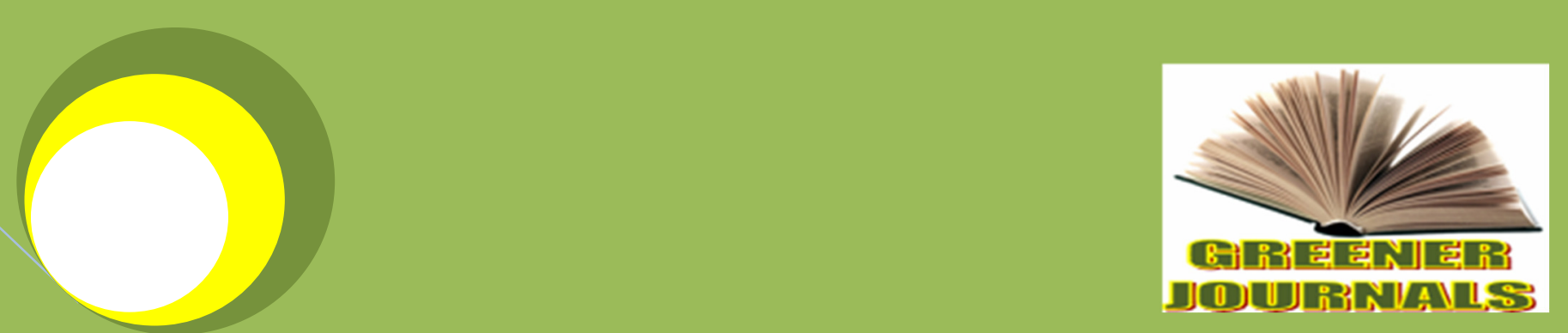

Greenerlournal of Social Sciences ISSN: 2276-7800 ICV: 5.99

Submitted: 31/10/2016 Accepted: 07/11/2016 Published: 30/11/2015

DOI: http://doi.org/10.15580/GJSS.2016.4.103116192

\title{
Girl-Child: Inclusive Quality Education, Agents of Socialisation and Sustainable Development in Nigeria
} By

Isola Abidemi Abiola Olasunkanmi Osundina 


\title{
Girl-Child: Inclusive Quality Education, Agents of Socialisation and Sustainable Development in Nigeria
}

\author{
${ }^{* 1}$ Isola Abidemi Abiola, ${ }^{2}$ Olasunkanmi Osundina
}

\author{
Babcock University llisan-Remo, Ogun State Nigeria. \\ ²Email:skm4me @yahoo .com \\ ${ }^{1}$ Corresponding Author's Email: jmineall @yahoo .com
}

\begin{abstract}
Inclusive quality education for a girl child is a cornerstone for sustainable development across the world. Education is a fundamental right of every individual with no gender discrimination whatsoever. Such right to education has been seen as catalyst for development since education empowers individual to increase their wellbeing and contribute to the society at large. According to well documented facts, improved education accounts for about 50 per cent of economic and social growth of developed countries. Hence, for education to deliver, it must be inclusive and high in quality. This inclusion which counteract gender discrimination advocate for girl-child education. In Nigeria, gender disparity has limited the enrolment of girl child to quality education and also to number of females who can contribute meaningfully to national development. To tackle this problem, inclusive quality education backup by policy to ameliorate challenges faced by the girl child is thus, imperative. This paper adopted descriptive methods in analyzing documented facts that are available via secondary sources of data, like extant textbook, journal, internet sources, relevant to this study with the aid of Liberal feminism Theory. The study therefore found out that various obstacles that stymie a girl-child from the fundamental right to education include; traditional attitudes, religion, poverty, geographical isolation, early marriage, pregnancy among many others. Conclusively, the paper acknowledges inclusive quality education as an indispensable means to annex every individual capabilities to attain economic development. Therefore, it is recommended that sustainable development can only be truly possible when gender discrimination is jettisoned by agents of socialisation for inclusive quality education of the girl-child in Nigeria.
\end{abstract}

Key Words: Girl-Child, Inclusive Quality Education, Sustainable Development \&Socialisation

\section{INTRODUCTION}

A girl child is a blessing, an asset and a precious stone that should be cherished and natured to a greater height. She is a creation of God as well as a boy child. A girl child is a human being. When a girl child is valued, human life is being valued. She is intelligent any has a reasoning ability, imaginative and creative. She is not some species on the verge of extinction we are talking about here. She is to be respected (Let Her Live). Therefore, the need for an inclusive quality education for a girl child which serves as a corner stone for sustainable development generally in Africa and in particular Nigeria. Inclusive quality education which is one of the goals of sustainable development goals (SDG 4) aims at ensuring inclusion and equality in and through education which is referred to as a cornerstone of transformative education agenda, in order to addressing all forms of exclusion and marginalization, disparities and inequalities in access, participation and learning outcomes in order to ensure that most disadvantaged in which girl child is one of them, is not left behind. (World Education forum, 2015). In achieving this goals in other to bring about national sustainable development, there is need for active participation of agents of socialization which include family, school, religious institutions, and mass media inter alia. To inculcate in a girl child, her worth, knowing fully well, that she is being groomed to be a woman in the future. It is believed that female children remain the best social security a family, can hope for while a male children are preoccupied with taking care of their immediate family, the female child, a woman has a high probability of remembering home (Mojekwu - chikezie 2012:141).

Women participation as catalyst in development cannot be overemphasized. However, they are faced with challenges like gender disparity, which has limited the enrollment of girl child to quality education in Nigeria. Without this 'weapon' of quality education, a girl child cannot be empowered to participate in decision Making process when it comes to public issues thereby preventing her from being empowered, politically, socio-economically and even culturally. This paper therefore, seeks to elucidate that if obstacles that stymie a girl child from fundamental right to 
education which include traditional attitudes, religion, poverty, early marriage pregnancy among others can be curbed or prevented through agents of socialization then, sustainable development is realistic. This paper is, hence, divided into four component which are the introduction, methodology, literature review and theoretical framework, challenges; conclusion and recommendation.

\section{METHODOLOGY}

The paper adopted descriptive method. It is useful especially in analyzing documented fact that are available and useful to achieve the objective of the paper. However, the paper adopted secondary source of data collection through relevant scholarly materials such as official bulletins, textbooks, journals, and internet source relevant to the study.

\section{LITERATURE REVIEW AND THEORETICAL FRAMEWORK}

\section{A Girl Child (Grown Woman), Gender Disparity and Inclusive Quality Education}

A girl child could be referred to as a female child or full grown. It could also be referred to as a young immature woman especially, formerly an unmarried one. However, in an informal definition which is sometimes offensive, a girl child can be referred to as a grown woman, especially when referred to familiarly. This paper adopts this informal definition of a girl child as a grown woman in the context of this paper. However, girl child, female child and woman will be used interchangeably.

Gender equality according to United Nations Educational, Scientific and Cultural Organization (UNESCO, 2016) is a global priority and it inextricably linked to its efforts to promote the rights to education and support the achievement of sustainable development goals, especially SDG4 (Ensure inclusive and equitable quality of education and promote lifelong learning opportunity for all) and SDG 5 (achieve gender equality and empower all women and girls). By this, UNESCO averred that the most discriminated against in the world at large and especially in Nigeria can be empowered enough to be able to participate in matters that relates to public issues/ governance in order for their voices to be heard. It is believed that, "gender inequality in education affects both girls and boys and women and men, but girls and women are still more often disadvantaged". (UNESCO, 2016). Gender inequality has continued to frustrate sustainable development because the male dominated social system has not given the women the attention, resources and motivation in critical areas of development in Nigeria (Yusuf and Yusufu, 2010).

In every society the roles women and men assume, accord women fewer opportunities and privileges. This role affect 'power to' and 'power over'. Power is having the proficiency to control and offer required access to social resources like education, money, land or time. Women usually have less "power to" go to school or refuse marriage for "power over" on the other hand, it is the degree to which they are able to assert their wishes and goals even in the face of opposition from others. Their voices are hardly heard especially in a male dominated society. They have less say than their husband in family decision and less authority than men in the work place because they have fewer positioning in governing bodies. Consequently, making little impact in decision making or public policies (Yusuf and Yusufu 2010). This is as a result of lack of education among women that stymie the active participation of women in sustainability of development in Nigeria. Therefore, the need for inclusive quality education for girl child. Inclusive quality education helps women to have access to information related to their rights economically, health wise, socially and in other ramification. Because it is when a girl child is educated that she can learn to read and write and even talk with confidence in their clime, by this means, making impact.

\section{ROLE OF AGENTS OF SOCIALISATION IN ENSURING INCLUSIVE QUALITY EDUCATION AND SUSTAINABLE DEVELOPMENT IN NIGERIA}

Socialization is all about the process through which an individual inherits the norms, custom and ideologies of the social order they live in. it is necessary because it enables an individual to interact within the society which shares common values custom, norms, traditions, languages etc. Socialization is a lifetime experience and such experience is made possible through agents of socialization. Socialization involves processes. This process of socialization is very important because it teaches one how to deport yourself in the society. Learning how to accept custom, norms, symbols, languages and behavior would have been difficult without socialization. In a society, an individual or institution has the task of inculcating the social order in an individual.

Through these agents of socialization, the transfer of rules, expectations, values, etc are carried out. Agents of socialization are both formal and informal or better still primary and secondary. Baxamsa $\left(\begin{array}{lll}2 & 011\end{array}\right)$. The primary 
agents of socialization include those people who are very close to an individual. They include family and friends. The most important primary agents of socialization is the family,which plays an important role in shaping the life and behavior of an individual in the society. It has been identified as the most important agent because it is within this institution that the process of socialization is both internalized and unconsciously learnt. Family is the initial source for transmission of culture to the child. While the secondary agents of socialization are those institution or places that helps an individual find where he/she belongs to within the society. These includes religious institutions, Schools, work places, etc. These agents help the individual to interact well with the society he/she belongs to. Baxamsa (2011). The following agents are thus discussed one after the other:

Family: According to Zenden (1965) family is the first social group in which the child holds membership, were he/she feels the sense of belongingness, hence, it is the first socializing agency in the child's life. A family is as the first socializing agency provides him/her with his most durable and intensive social relationships. According to Herbert Spencer (cited in Bourne, 2006), the development of the family stands first in socialization. Macionis and Plummer argued that Charles Darwin supports the view that human nature leads us to create and learn cultural traits. "The family is the most important agent of socialization because it represents the centre of children's lives (Macionis and Plummer, 1998). Beard in Bourne (2006) believed that mothers should be appropriately called "constant, carriers of common culture". This emphasizes the very principal tunnel to which mother guide their young and they are equally conducts of the transfer of values, norms, ideology and perspective on the world for their children. Infants are almost totally dependent on others (i.e. family) for their survive ability especially mothers, thus, the need for a year or two years of maternity leave should be given to mothers with pay so they have enough time to nurture their children in a good and acceptable way rather than leaving them in the hands of strangers that are likely not to nurture them in an acceptable way to the society. These explain the pivotal role of mothers and/or other family member. The socialization process begins with the family and more so those individuals to which the child will rely for survival. This happening emphasizes how the child is fashioned into a human, and not merely because of birth. The child learns to speak, the language, actions mode of communication, value system, norms and the meaning of things through adoption, repetition, and observation of social actions of people within the environment. The process of becoming a human is simply performed by the family (Bourne,2006). Hence, it is expected of the family when performing the role of a child becoming human to ensure that love is shared amongst the children whether male or female. If it is a family girls, they should imbibe in them the culture of respecting personality no matter the sex. On the other way round, If boys, the father of such home should learn to teach by example by treating his wife, the mother of his children with respect thereby passing across the importance of respecting other women and girl child outside home. Furthermore, when it comes to division of chores at home, this should not be done based on sex. Boys and girls should learn to help around the house including cooking in the kitchen and running errand for parents. When it comes to education, both male and female should be educated and non should be encourage to go into early marriage because of lack of funds thereby using that opportunity to sponsor any of the sex especially boys. None should be discriminated against based on education.

School: Bother - Jennings (2008) posit that school socialize children by teaching them their formal curriculum but also a hidden curriculum as well. The formal as to do with reading, writing and authentic. But the latter as to do with importation of cultural values of the society in which the school are found. In Nigeria for instance at the Nursery/Primary level teacher teaches subject like Civic Education which preaches moral values/social norms/ that as to do with respect for others/elders integrity, honesty, etc. Similarly Adebayo (2010) sees a school as a place of learning. It is an educational institution, where skills, values, knowledge and attitude can be acquired. It is a micro system next to the family. School is the first place, where children begin interaction with others in the public environment. It is there they meet new friends, learn our society norms and good moral values. Some of the social norms is that children should not look down on anyone either male or female. Also students (children) are taught to cut grass, plant crops, learn how to sew, know how to cook as well in subject like agricultures and home economics respectively. Song like this are also sang at either primary or secondary level in Yoruba language which goes thus,

\footnotetext{
"Ise agbe ni ise ile wa

Ni ko sise amajale

Iwe ki ko lii se o ko

Ati Ada,

Ko I pe o (2x)"
}

Meaning "farming is a good work and it is the work of our land, whosoever does not work will surely steal. Education without knowing how to use your land is incomplete." This is the reasons why subjects as mentioned above are taught in schools. This is to instill in children that stealing is not good and that everyone is expected to work either 
male or female. Whoever is lazy and idle will definitely steal which is contrary to the policy of the clime we all belong too. All these teachings are to make children a contented, responsible adult either male or female when they become one.

Religion: Religion plays a very critical role in social life in Nigeria. As in many parts of the world Simbine (2005). Marshall (2005) in Simbine (2005) argued that religion has marked importance for Africa across many dimensions. It is given a prominent place among Nigerians even in daily living. A very good example is that of the number of churches and mosques and the rate at which they grow as well as posters that adorn streets, billboards and even vehicles in many cities and town. Virtually advertising the activities/programmes of one religion or the other. This shows importance of Nigeria in particular and Africa in general. Hence, the two religion should frown at bad act including discrimination based on sex which is the main focus of this paper. Everyone, irrespective of his/her culture, believes in the existence of God which can be referred to as religion. All these religion are expected to recommend moral standards which regulate human behavior, they should serve as agent of social orientation, through participation in religious activities. Irrespective of our sex, cultures, race or status, our religion either Christian or Muslims preaches of peaceful co-existence of the people by tolerating one another. Consequently, since all these religious institutions believe in God and as earlier stated in this paper that a girl child is the creation of God, thus a female child should be treated as someone indeed created by God. When both the primary and secondary agents of socialization work together and make impact it go a long way to help the nation to develop/progress because discrimination base on sex will be fought against and sustainable development, inevitable.

\section{THEORETICAL FRAMEWORK}

Liberal feminism evolved from liberal political school of thought or ideology. It is associated with the concepts of: Justice, Liberty, Autonomy, Rationality, Individuality and Egalitarianism. Notable liberal feminists include Mary Wollstonecraft, J.S Mills, Harriet Taylor, Betty Friedan, just to mention few. Akindele,2003; Standford encyclopeadia of philosophy,2007).

Liberal feminism has been motivated mainly by a desire to overcome overt forms of discrimination; in marriage, educational opportunities, legal rights and above all, the right to vote (Manyonga, 2007). The fight for the right to vote was won in the United States in 1920 (Ball and Dagger 1991: 208 cited in Adeogun\& Isola, 2011), with the ratification of the nineteenth Amendment to the constitution. The removal of these and other legal and institutional barriers has been the aim of liberal feminists. Their goal has been to give women the same rights and opportunities that men enjoy including education either formal or informal. They are not against men but propose that women should work with men in the development of the society. They therefore, stress on partnership with men and to them this can be achieved only when the society grants women equal legal, political and economic rights with men. (Ball 9and Dagger 1991: 208 cited in Adeogun\& Isola 2011;lloh et al(2009)

\section{CHALLENGES OF INCLUSIVE QUALITY EDUCATION FOR A GIRL-CHILD IN NIGERIA}

Education is an important transformative agent that enhances the status of an individual in a society. It has also been recognised as a fundamental strategy employed for development. Hence, inclusive quality education for the girl-child is not just an objective in itself, but a fact to accelerate political, social and economic advancement of a society. It must be noted that no sustainable development is possible when gender discrimination and marginalization is celebrated or promoted in the society. According to the United Nations International Children's Emergency Fund (UNICEF, 2007) revealed that girl's education does not only bring the immediate benefits of empowering girls, but it is seen as the best investment in a country's development. Consequently, educating a girl-child is fundamental if development, particularly in developing countries like Nigeria, is to bring about political and economic development. However, certain fundamental issues still mitigate against quality education of the girl-child education in Nigeria.

Girl-child education is fundamental because of its functional impact on human development and the society as a whole. Therefore, the implication of discrimination on inclusive quality education for the girl child will breed undereducated women, which invariably will result into high risk poverty, maternal mortality, child mortality, less skilled women population, all culminate to affect the political, social and economic development of their communities. As a result, this paper has identified certain challenges confronting strong establishment of quality inclusive education of the girl-child which have, thus, hinder national development, as traditional attitude, religion, poverty, early marriage, pregnancy and geographical isolation. These factors are seen as eroding positive perspective of empowering a girl through education. Discussion on each of these concept and their aftermath effect are as follows; 
Traditional Attitude towards the Girl Child: Presently, as said earlier, certain elements affecting girl child inclusive quality education and sustainable development are the indicators mentioned above. These cultural barriers and environmental manipulation according to Uzoma (2013) create inferiority complex in many Nigeria women. Oniye (2010) while contributing to this problem is of the opinion that tradition is a constraint on the girl child education. He ascertained that through the traditional socialization process of our cultural society where women tend to accept negative self-fulfilling prophecy, stereotyping and stigmatization. Hence, socialization process of value and norms place on the male child is different from that of the girl child, and this invariably interplay adversely in the national agenda.

Furthermore, Oniye (2010) also believed that traditional attitude of daughter perception by parents towards female education is equally negative. Many parents see investment in a son to be better than that of a daughter, as daughter are perceived to be less valuable once educated, and less likely to abide by the will of the father, brother or husband. This traditional attitude, in term of education, has compounded quality education for the girl child in Nigeria.

Religion Perspective Reasons: Religion can be seen as the belief system of a community. This belief systems are the regulating values that determine the way of life of the people in term of teaching, moral, supernatural perception which are fused into custom, culture and socialization process of the community. Therefore, in the political and social life of a community, gender role issues become a defining line of activities. No wonder, in some part of Nigeria, mostly; the Northern part, religion most time do not support the empowerment, education and equal right of the male to the female.

For example, Sokoto is the seat of the Caliphate where Islam faith is an integral part of the society. Religion here has influenced perception when it comes to the aspect of education mostly among the girl child. The educational systems are guided and influence by Islam, as a result of the prevalence of Islam, religious beliefs therefore play a significant part in moulding social behaviour, the religious and value differences also have a bearing on the attitudes of various group towards female children's education. For example, the Muslims exhibit more conservative attitudes toward women in general and (western) education in particular and consequently their women have made the least development with respect to (western) education.

This is one major reason why the World Bank (2006) argues that some tenet of Islamic religion could easily be misinterpreted and used to prevent female participation in education such as restriction of girls from appearing in public places or to mix up with the opposite sex. Consequently, rural girls drop out at a much higher rate for social, family and religious reasons more than for education-related reasons.

Early Marriage of the Girl-Child: Furthermore, the above positions submitted from traditional attitude and religion perspectives make early marriage of the girl child fashionable. This disparity and disenfranchisement of the girl child in the public sphere ultimately allows men dominate both public and private sectors leading parents to submit and asking question: why bother to educate the girl child since the business world is dominated by men and eventually the girl child will end up in the kitchen?

Poverty: Answering the above question will advance our knowledge on poverty-cycle system in many developing societies. According to the U.S Agency for International Development and the World Bank, 57 percent of the 72 million primary school aged children who do not attend school are female. Additionally, girls are four percent less likely than boys to complete primary schools (Gender Statistics, 2010). Generally, girls in the poorest 20 percent of household have the lowest chance of getting an education (Jensen, 2010). Moreover, statistics show that of the 774 million illiterate adults worldwide, 64 percent are women, a statistic virtually unchanged from the early 1990s (Gender Statistics, 2010).

Nigeria has performed poorly in term of gender equality too. According to the 2012 Gender in Nigeria Report, data suggest that Nigeria ranks 118 out of the 134 countries in the Gender Equality Index. The results of these findings, most especially the one on Nigeria established the reasons behind poverty ridden situation of the country. According to Uzoma (2013), educating girls is an important step in overcoming poverty and ensuring economic development. An educated girl according to him is an empowered individual who is more marketable in terms of employment. Better employment in turn implies more earnings for the family as a whole, as well as improved children's well-being. All of which contribute to poverty reduction and economic growth.

Pregnancy: Early pregnancy has been observed as another key factor mitigating against the girl child for education. In a research concluded by Adella (2014) it was observed that various male participate, explained the way this problem dissuaded parents from sending girls to school. They therefore opted to marry off the girl rather than wasting cattle, which according to them would give them a quicker income than using the little resources sending the girls to school. The above argument supported Hunt's (2008) observation that pregnancy had become a significant cause of drop-out for teenage girls. It was also evident from research undertaken in 2011 by the Pastor Women Council 
(PWC), in Temba et al (2013) which found Moran or young Marasa warrior were tasked by the community elders to get young girl pregnant so that they could be forced to drop out of school. This implied, therefore, that this practice was purposely done to limit girl's enrolment in school. This also echoed Raymond's (2009) findings that parents in Menduli value assigning their daughter husband rather than giving them exercise books and pens to go to school.

Geographical Isolation: The geographical factor is significant in the education of a girl child in Nigeria. The reason is that female security and distance to school site is a major decision making in enrolment pattern by parents. Due to many traditional perceptions of the rural dwellers, female security and access to primary schooling combine to the extent that a distance of more than 2 kilometres operate can hinder a girl child take-up primary schooling activities. Though, enrolment levels vary from region to region. For example, the urban/rural dichotomy is striking when it comes to enrolment exhibiting a "core-periphery" pattern. Question of remoteness and accessibility within region, isolated, traditional villages in the interior have a different attitudes towards the role and status of women and the education of girls from those on the coast or city side. Attitudes to girls' education according to Colin and Nadine (1997) are significantly different in the more rural areas, families are larger and access to school is more difficult.

\section{CONCLUSION AND RECOMMENDATIONS}

This paper explains the perception behind the inclusive quality education for the girl-child. It went further to explain the positive functional importance of empowering the girl child through the agents of socialisation as well as the relationship between the girl-child and sustainable development in societies. However, findings identified certain impediment working against educating the girl-child as traditional attitude, religion, early marriage, poverty, pregnancy and geographical isolation. Although since 1980s government policy has been geared towards limiting disparity of educating the girl child, notwithstanding, perception and attitudes of some parents in some region, most especially the Northern part of Nigeria and in areas where value placed on the girl is of no real economic value, still denial equal enrolment of the girl child to that of the male.

Thus, the paper suggest that consideration of the contextual circumstances of the girl-child in marginalized societies is needed in order to stop gender discrimination and for the country to attain sustainable development. Hence, inclusive quality education of the girl-child in Nigeria is paramount. Based on the above findings, the paper therefore recommend the following:

Government need to put in place policies that create an environment where girls have access to school and can learn effectively. Issues of security, distance, and traditional stereotyped perception towards the girl child must be addressed according to policy.

The enforcement of the Girl-Child Act in all states in Nigeria is paramount in order to foster equal right of the female child with that of the male child. Hence, government need to galvanise the political momentum in which courageous policy action can be taken. Actions are needed that challenge the existing structures and systems that keep girls from realising their right to basic education.

The fight against early marriage should be intensified by many through collaboration with the government. By so doing, girls will be empowered and their future secured.

There should be a paradigm shift towards sensitization and need of educating the girl-child because of its socio-economic importance in the political life of a nation. The present effort by ministries saddled with this responsibility are not effective enough. Hence, this agency must be particular to go to hinterland or rural regions where traditional attitude and leaders' perception heavily shaped the decision of parents towards inclusive quality education of the girls.

\section{REFERENCE}

Adebayo, S. (2010). Essentials of Social Studies, Upper Basic Education. Extention Publications limited.Ibadan. Adella, P (2014) Girls' Education in Pastoral Communities: An Ethnographic Study of Monduli District, Tanzanin.

Abbort, P, Wallacc, C and Tyler, M (2005) "An introduction to sociology: feminist perspectives" cited in Haralanbos and Holborn "sociology: Themes and perspectives $7^{\text {th }}$ edition. Harper Collins publishers Limited. London.

Adeogun, T and Isola, A. (2011):"Evaluation Of Women's Rights In The Perspective Of Human Rights Under Democratic Government In Nigeria. (1999-2009)". Babcock University of Management and Social Sciences. Vol. 8 No. $1 \& 2$

Akindele, S.T (2006) "Local Government and Grassroots Democracy in Nigeria, under Fourth Republic. cited in Inyama,(ed.) Long Essay submitted to the Department of Political Science. Obafemi Awolowo University. Ile -Ife Osun State. 
Batul Nafisa Baxamsa http:// www.buzzle.com/articles/agents of socialization html 8:15pm on $15^{\text {th }} / 03 / 2012$

Bourne, P. (2006). Socialization: The role of family, school and political institution.

Colin, B and Nadine, C (1997) Factor Affecting Female Participation in Education in Seven Developing Countries: Education Research Paper, No 09, pg (96). Universitties of Oxford and Hull.

Education 2030: towards inclusive and equitable quality education and lifelong learning for all. www.globalpartnership.org.content/inclusive-quality-education-all-children-disabilities.

Gender in Nigeria Report (2012). "Improving the lives of women and girls in Nigeria: Issues, Politics and action". British Council, Nigeria, 2012.

Gender Statistics (2010) "Improving the lives of women and girls in Nigeria: Issues, policies and actions. British Council, Nigeria, 2012.

Gender Statistics (2010) United States Agency for International Development. http://www.usa.d.goo/our_work/crosscutting-programs/wid/wid_state.html. Accessed July 24, 2016.

Hunt, F (2008) Dropping out from school, a cross country review of literature CREATE Pthways to Access. Research Monograph no. 16. Falmer UK: University of Sussex.

Iloh, E. C . (2009). Electoral Process and Gender Discrimination in Nigeria a case study of 2003 and 2007 General Election. Journal on sustainable Development in Africa.

Jensen, $\quad \mathrm{L} \quad$ (2012) Millennium http://www.un.org/millenniumgoals/MDG_Report/pfd/MDG\%202015\%20rev\%20. Accessed July 28, 2016.

Let Her Live: Ensuring the Dignity and Equity of Women and Girl Children. www.http://letherlive.in/blog/why-valuegirl-child.accessed 20/07/2016.

Macious S.S, Plummer K, (1988). Sociology, New York: Prentice Hall

Manyonga, F (2007): feminist literacy Theory: A Christian Approach. Cited in Corruption and the challenge of human development. A publication of the program on policy, conflict and strategic studies. Babcock University.

Mojekwu - chikezie; N (2012): African women: sentenced by tradition. Pragmatic educational press. Lagos Nigeria.

Oniye, A (2010) "Women Education: Problems and Implications for Family Responsibility: The Nigerian Journal of Guidance and Counselling.

Raymond, A (2009) Under-representation of pastoral community in primary education in Tanzania: The case of Monduli: District. Unplished MA (Education) dissertation, university of Dar-es Salam.

Temba, E, Warioba, L \& Msabila, D (2013) "Assessing effects to address cultural constraints to girls' access to education among the Maasai in Tanzania: a case study of Monduli district". Journal of International Cooperation in Education, 15(3), 21-37.

United national educational scientific and cultural organization (UNESCO).www.UNESCO.ORGS. World education forum 2015.www.

Yusuf \&Yusufu (2010): Gender inequality, A challenge to sustainable development in developing Nations: The way forward. International conference on Research and development, Vol 3. No 32.

Zanden,J.W (1965). Sociology,A systematic Approach.The Roland press company,New York.

Cite this Article: Isola AA, Osundina O (2016). Girl-Child: Inclusive Quality Education, Agents of Socialisation and Sustainable Development in Nigeria. Greener Journal of Social Sciences, 6(4): 106-112, http://doi.org/10.15580/GJSS.2016.4.103116192 